\title{
LA “REVOLUCIÓN SEROTERÁPICA" EN BUENOS AIRES. TENSIONES $Y$ ARTICULACIONES POLÍTICAS Y PROFESIONALES EN TORNO A LA INVESTIGACIÓN CIENTÍFICA Y LA PRODUCCIÓN DE SUEROS (1894-1904)
}

\author{
Nicolás Facundo Rojas \\ CONICET, ISCo-Universidad Nacional de Lanús, Argentina. \\ Email: nicolasfac.95@gmail.com \\ ORCID iD: https://orcid.org/0000-0001-6907-6001 \\ Juan Pablo Zabala \\ CONICET, ISCo-Universidad Nacional de Lanús, Argentina. \\ Email: jpzeta@hotmail.com \\ ORCID iD: https://orcid.org/0000-0002-1950-6517
}

Recibido: 27 marzo 2020; Aceptado: 30 mayo 2021

Cómo citar este artículo/Citation: Rojas, Nicolás Facundo; Zabala, Juan Pablo (2021) “'La revolución seroterápica' en Buenos Aires. Tensiones y articulaciones políticas y profesionales en torno a la investigación científica y la producción de sueros (1894-1904)" Asclepio, 73 (2): p569. https://doi.org/10.3989/asclepio.2021.27

RESUMEN: Este trabajo analiza la recepción de la seroterapia en Argentina a fines del siglo XIX. Nuestro argumento es que la incorporación de la seroterapia y el desarrollo de agentes terapéuticos supuso una serie de cambios significativos en el campo sanitario en tres dimensiones: a) en las políticas sanitarias, por la incorporación de la función de investigación y producción de agentes terapéuticos por parte de la principal autoridad sanitaria (en relación estrecha con la Escuela de Medicina de Buenos Aires); b) en la práctica profesional, por los cambios que introdujo el trabajo experimental en la relación médico-paciente; y c) en la configuración social del campo médico sanitario, donde a partir de una serie de disputas y conflictos se consolidó el liderazgo de un grupo de médicos ligados a la bacteriología. De este modo, esta nueva terapéutica fue un dinamizador de la actividad y tuvo una incidencia importante en la trayectoria de diferentes actores sociales y espacios institucionales ligados a la salud en el Buenos Aires de fines del siglo XIX.

PALABRAS CLAVE: Seroterapia; Enfermedades Infecciosas; Bacteriología; Departamento Nacional de Higiene; Argentina.

\section{THE “SEROTHERAPIC REVOLUTION” IN BUENOS AIRES. POLITICAL AND PROFESIONALS TENSIONS AND JOINTS AROUND A SCIENTIFIC RESEARCH AND SERUM PRODUCTION (1894-1904)}

\begin{abstract}
This work analyzes the reception of serotherapy in Argentina at the end of the 19th century. Our argument is that the incorporation of serotherapy and the development of therapeutic agents represented a significant changes in the health field in three dimensions: a) in health policies, by the incorporation of the research and production function of therapeutic agents by the main health authority (closely related to the Buenos Aires School of Medicine); b) in professional practice, due to the changes that experimental work introduced in the doctor-patient relationship; and c) in the social configuration of the health field, where a group of physicians consolidated from its leadership through a series of disputes and conflicts. In this way, this new therapy was a catalyst for activity and had an important impact on the trajectory of different social actors and institutional spaces linked to health towards the end of the 19th century.
\end{abstract}

KEY WORDS: Serotherapy; Infectious Diseases; Bacteriology; Departamento Nacional de Higiene; Argentina. 


\section{INTRODUCCIÓN}

Marzo de 1901, ciudad de Buenos Aires. José Penna, director de la Casa de Aislamiento, se encuentra al pie de la cama de un paciente, un almacenero italiano de cuarenta y tres años, uno de los tantos afectados por una enfermedad infecciosa que se encuentran allí internados. Ha pasado la noche observando sus síntomas, y ahora, luego de medir su temperatura, tomar el pulso y palpar la zona de la ingle, hace una anotación en su historia clínica:

[...] Noche tranquila; la cefalgia cesa, el rostro se anima, los dolores de la ingle disminuyen, y al lado de este cuadro real de mejoría la fiebre continúa estacionaria pero á un nivel más inferior que los días anteriores. La declinación febril, aunque lenta, alcanza definitivamente la normal el 22, justamente al quinto día de iniciada la enfermedad. Los demás síntomas mejoran también, no quedando sino el infarto ganglionar, duro, poco sensible, y una gran debilidad muscular. ${ }^{1}$

Con síntomas similares, desde el año anterior al menos setenta pacientes fueron remitidos desde los hospitales y servicios de socorro de la Asistencia Pública al "servicio de Penna", donde se desempeña un grupo de enfermeras, estudiantes y médicos veteranos. Son los primeros casos de habitantes de la ciudad, en su mayoría estibadores y trabajadores de los almacenes de granos, contagiados con la temible peste bubónica. La pandemia había llegado al sur del continente luego de surcar Asia y Europa (Bramanti et al., 2019), y su manejo inicial provocó un escándalo que forzó la renuncia del Director del Departamento Nacional de Higiene, Eduardo Wilde, y su reemplazo por Carlos Malbrán.

Penna, sin embargo, actúa con tranquilidad ante la llegada de estos pacientes. En la Casa de Aislamiento se emplea un tratamiento al que tanto él como el resto de la élite médica reconocen una comprobada efectividad, y cuyos secretos les enseñó minuciosamente a los médicos de su servicio desde hacía al menos cuatro años atrás, cuando aún eran estudiantes. Dicho tratamiento, cuyos efectos en el organismo son monitoreados de forma exhaustiva mediante historias clínicas, consiste en dos inyecciones intravenosas "masivas" de una sustancia cristalina y espesa almacenada en pequeñas ampollas de vidrio selladas a la llama: sueros antitóxicos preparados en el Instituto Pasteur de París, un frágil y codiciado objeto que escasea en ese momento en la ciudad y en el resto del país.

Tan solo a un par de kilómetros de distancia de la Casa de Aislamiento, en un establo construido preca- riamente, dos empleados del Departamento Nacional de Higiene vestidos con guardapolvos blancos rodean a un caballo. Mientras uno sostiene su cuello, el otro clava una larga aguja con una manguera a la vena yugular del equino. La sangre comienza a llenar un frasco de vidrio frente a los ojos de ambos. Mientras tanto, un veterinario transporta a otro caballo desde su corral hacia los hombres de guardapolvo, a la espera de ser "sangrado".

Junto al establo, en el interior de un pequeño edificio acondicionado como laboratorio, el movimiento es frenético. Un empleado observa a través del microscopio unas pequeñas placas de vidrio pobladas por colonias bacterianas coloreadas con distintos tonos de azul, mientras un segundo coloca instrumental en una estufa de desinfección; más allá, otro empleado deposita tubos de ensayo sellados con algodón en un extremo sobre una pequeña mesa cubierta por una campana de vidrio. Alrededor de una serie de grandes frascos ordenados en fila sobre una mesa, inclinados y repletos casi hasta el borde de un líquido espeso y oscuro, un empleado llena a través de mangueras de caucho pequeñas ampollas de vidrio, que luego sella con la llama de un mechero. En otra mesa, un par de peones etiquetan las pequeñas ampollas de vidrio. La leyenda estampada en la etiqueta reza: Suero antidiftérico. Departamento Nacional de Higiene - República Argentina, 200 Unid. antitóxicas, $10 \mathrm{~cm}$. Cúbicos.

En otra de las habitaciones del edificio, el jefe de empleados, Juan Carlos Delfino, escribe un informe dirigido a Carlos Malbrán, presidente del Departamento y su colega en la cátedra de Bacteriología de la Facultad de Medicina de la Universidad de Buenos Aires, también antiguo maestro y compañero de trabajo, sólo algunos años antes, en otro laboratorio de la agencia. Debe informar a las autoridades sobre la organización del trabajo en el laboratorio; acaba de ser nombrado a cargo luego de regresar de un viaje por Estados Unidos e Italia, donde conoció la enorme factoría seroterápica de Parke-Davis, en Detroit, y el Real Instituto de Higiene dirigido por Angelo Celli (1857-1914) en la Universidad de Roma. Tiene, entre sus apuntes sobre anopheles de Santiago del Estero, estudios estadísticos que detallan el número exacto de unidades de suero producidas y entregadas a los Consejos de Higiene de las provincias durante el año anterior, los resultados de los exámenes practicados sobre las aguas corrientes de la ciudad, algunos informes médico-legales, exámenes histológicos solicitados por los médicos de los hospitales y pruebas hechas sobre las placas de cow-pox del Conservatorio Nacional de Vacuna. Parte de estos 
informes se publicarán en los Anales del Departamento Nacional de Higiene unos meses después:

En el año 1902, se han distribuido los siguientes frascos de suero: Capital Federal, 38; Provincias: Buenos Aires, 20; Corrientes, 18; Córdoba, 12; Catamarca, 10; Entre Ríos, 32; Salta, 5; San Juan, 30; Pampa Central, 12; total, 192. Siendo de importancia para nosotros la vacunación por el método de Haffkine, en casos de amenaza de propagación epidémica de peste bubónica, en la oficina bacteriológica se prepara la vacuna preconizada por el médico ruso [...]. En lo que atañe a la producción de suero antipestoso, se ha marchado con lentitud por falta de local apropiado á este género de trabajos, nada exento de peligro; pero es de esperar que mejorando las condiciones de instalación, será posible dedicarse á preparar el medicamento específico contra la peste bubónica. ${ }^{2}$

Este pequeño grupo de empleados del Departamento Nacional de Higiene es parte del "personal técnico" de la Sección Seroterápica de la Oficina Sanitaria Argentina, creada casi diez años antes en el marco de la reorganización interna de la agencia. El precario edificio construido junto al establo, un espacio de convivencia entre veterinarios, médicos y bacteriólogos, está acondicionado especialmente para producir sueros específicos, como los utilizados por el "servicio de Penna" en la Casa de Aislamiento ${ }^{3}$.

El relato previo, reconstruido a partir de distintas notas de los protagonistas, nos permite mostrar la diversidad de intereses (políticos, profesionales, económicos), espacios institucionales (hospitales, laboratorios, organismos administrativos y la Escuela de Medicina) y profesiones (principalmente médicos, pero también veterinarios) que, en forma superpuesta, se vincularon a la recepción de la seroterapia en la Buenos Aires de fines del siglo XIX.

Este proceso debe entenderse en el marco de los profundos cambios que supuso la bacteriología en el conocimiento y tratamiento de las enfermedades infecciosas que, además del desarrollo de tratamientos originales, implicó la adopción de un nuevo paradigma cognitivo (la teoría microbiana), la preeminencia otorgada al trabajo de laboratorio y una modificación en las políticas de prevención. Vistos en una escala temporal que abarca el último tercio del siglo XIX y principios del $X X$, la profundidad que implicaron estos cambios en la organización intelectual y social del mundo científico-médico ha llevado a numerosos historiadores a utilizar la idea de "revolución bacteriológica" para ca- racterizar este período (Rosenberg, 1987; Cunningham y Williams, 1992).

Al mismo tiempo, el carácter revolucionario de las prácticas bacteriológicas era parte del discurso esgrimido por los protagonistas de nuestra historia, tal como se ve en el siguiente pasaje de José Penna:

...puede decirse que el tratamiento de esta enfermedad (difteria) ha pasado por tres periodos distintos [...] El tercer período, el actual, clasificado con toda propiedad periodo de la sueroterapia, empieza con los progresos de la bacteriología [...] El reinado de la sueroterapia contra las enfermedades infecciosas tóxicas se halla todavía en su infancia, pero no puede negarse que en vista de los resultados obtenidos hasta el presente, la constituyen en una medicación maravillosa y llena de grandes promesas en un porvenir cercano. ${ }^{4}$

Sin embargo, otros historiadores como Worboys $(2000,2007)$ han cuestionado la existencia de una "revolución bacteriológica", en el sentido estricto de una transformación radical y total. En cambio, proponen que la adopción de la bacteriología se dio mediante un proceso de adaptación y adición, en el que los nuevos conocimientos se integraron a los paradigmas vigentes en la época, como el humoral o el miasmático, enfatizando las continuidades con las teorías y prácticas anteriores.

En un período temporal como el que tomamos en este artículo, y en un espacio profesional que estaba aún en proceso de configuración, la naturaleza de los hechos analizados parece haber tenido un carácter más cercano al propuesto por esta última interpretación. Aun así, nuestro argumento es que en torno a la incorporación del tratamiento seroterápico se dieron una serie de cambios significativos en el campo sanitario local, que nos ayudan a comprender el alcance más general que significó la incorporación de la bacteriología en los años siguientes. Nos interesa analizar estas consecuencias en tres dimensiones: a) en la políticas del Departamento Nacional de Higiene (a partir de ahora $\mathrm{DNH}$ ), principal autoridad sanitaria nacional, que asumió definitivamente el paradigma bacteriológico e incorporó la función de investigación y desarrollo; b) en la práctica profesional, donde la incorporación de esta tecnología introdujo un cambio en la relación médico paciente, y fue crucial para el posterior desarrollo del rol de científico; y c) en la configuración social del campo médico sanitario, donde a partir de una serie de disputas y conflictos se consolidó el liderazgo de un grupo de médicos que luego dirigirían la principal apuesta institucional de la bacteriología en las décadas siguientes, el Instituto Bacteriológico del DNH. 
Para el análisis de este proceso fueron utilizados como materiales empíricos los principales periódicos y órganos de comunicación de la escuela médica de Buenos Aires de fines del siglo XIX, memorias institucionales, trabajos científicos y expedientes de archivo. Se practicó una lectura secuencial de estos materiales con el objetivo de rastrear "huellas e indicios" en el conflictivo proceso de circulación y reconfiguración de los conocimientos seroterápicos en el espacio local (Ginzburg, 1999; Roberts, 2009). Como fechas extremas, tomamos el año en que se publicaron en Buenos Aires los primeros trabajos sobre seroterapia, 1894, y como fin la colocación de la piedra fundacional del Instituto Bacteriológico, en 1904.

\section{EL DESARROLLO DE LA SEROTERAPIA EN EUROPA Y SU RECEPCIÓN EN ARGENTINA: TENSIONES INSTITUCIONALES POR EL CONTROL SANITARIO Y LA PRODUCCIÓN DE SUEROS}

La seroterapia tiene ya su himno. Son los alemanes los creadores del canto al antidiftérico Roux. En un círculo médico de Berlín, cierto joven doctor ha improvisado una canción sobre la vacuna de la difteria [...] He aquí un trozo de esta Marsellesa de la inoculación: el pedido es grande y la provisión pequeña. La inoculación cuesta 16 marcos. Esto es precio caro. Así, almas bienhechoras, acudid en tropel -y procurad los medios necesarios. -iOh Suero! iSuero! iSuero!-iLo que falta todavía es el nervus serum! ${ }^{5}$

La seroterapia supuso, a partir del desarrollo del paradigma bacteriológico iniciado en la década de 1880, una novedad promisoria para el tratamiento de un conjunto de enfermedades infecciosas, lo que atrajo la atención de diversos actores e instituciones vinculadas al cuidado, el control de la salud de la población y la producción farmacéutica. Esta consistía en un tratamiento antitóxico basado en la inyección de suero de caballo inmunizado, cuando los pacientes se encontraban cursando una enfermedad, y fue desarrollada en conjunto entre los dos principales institutos de investigación bacteriológica de Europa central, el Instituto Pasteur de París y el Instituto de Enfermedades Infecciosas de Berlín. Así, durante la segunda mitad de la década de 1890 y durante los primeros años del 1900, la élite médica local experimentó en el ámbito clínico con sueros para tratar enfermedades infecciosas como el tétanos ${ }^{6}$, el carbunclo ${ }^{7}$, la peste bubónica ${ }^{8}$ e, incluso, el cáncer ${ }^{9}$, aunque fue la seroterapia antidiftérica la que finalmente tuvo una mayor difusión.

El primer paso en el surgimiento y desarrollo de los tratamientos con sueros comenzó con los estudios so- bre la inmunidad adquirida por la acción de las toxinas tetánicas y diftéricas, llevados a cabo por Emil von Behring (1854-1917), integrante del Instituto de Higiene de Berlín dirigido por Robert Koch, y su colaborador Shibasaburo Kitasato (1853-1931), del Instituto de Higiene de Tokio, publicados desde inicios de la década de 1890. En estos trabajos, ambos bacteriólogos profundizaban la línea de investigación que inicialmente los había llevado a indagar, luego de la identificación de la bacteria productora de la difteria por Friedrich Loeffler en la primera mitad de 1880 , en la respuesta antitóxica producida por la inoculación de toxinas en el cuerpo de pequeños mamíferos (Gradmann, 2010).

Estos fueron continuados por múltiples trabajos realizados tanto por Behring como por algunos colaboradores del Instituto Pasteur, en los que se concluyó, luego de la experimentación en conejos y cobayos, que el suero extraído de la sangre de pequeños animales inmunizados por la acción de las antitoxinas podía ser inoculado en otros organismos como tratamiento terapéutico. En 1894, Erich Wernicke (1859-1928) publicó una serie de trabajos junto a Behring donde daban cuenta de la aplicación del tratamiento a dos niños en el Hospital de la Charité a partir de suero extraído de perros. Unos meses después, Emile Roux y Louis Martin hicieron lo propio practicando la inmunización y extracción de suero de caballo en Francia, para luego continuar con la experimentación en niños en el Hospital de Enfants Malades (Gachelin, 2007; Hüntelmann, 2007). Era el nacimiento de la "serum-terapia" basada en la producción de sueros terapéuticos elaborados con toxinas específicas, entre los cuales el suero para tratar la difteria se posicionó rápidamente como un desarrollo "exitoso" (Simon, 2008).

A partir de estos desarrollos, ambos institutos bacteriológicos tuvieron en la producción de sueros una fuente importante de ingresos económicos y de legitimidad científica (Opinel, 2007). El Estado Imperial alemán tuvo la tutela del proceso de producción y comercialización de los sueros (Rüdiger Prüll, 2010). El Instituto Pasteur, en cambio, pasó a controlar directamente, desde el Comité del Suero de la Academia de Medicina creado en 1894 -cuyos integrantes pertenecían a la institución-, los estándares de producción y comercialización del suero antidiftérico, consolidándose como una firma de alcance global, una institución de referencia en el campo de la biomedicina mundial y un exponente de la ciencia colonial francesa (Gachelin, 2007; Moulin, 1992; Opinel, 2008).

En Buenos Aires, la irrupción de la seroterapia motivó distintas iniciativas orientadas a profundizar su co- 
nocimiento y, sobre todo, a garantizar su producción en el ámbito local por parte de las instituciones gubernamentales, en un contexto en el que las enfermedades infecciosas ocupaban un lugar central en la agenda sanitaria (Armus, 2000; Crider, 1976). De hecho, los recurrentes focos de fiebre amarilla y las sucesivas epidemias de cólera de las décadas de 1880-1890, a las que se sumó en 1900 la aparición de la peste bubónica, acaparaban la atención de las agencias encargadas de la vigilancia sanitaria. Principalmente, del $\mathrm{DNH}$, creado en 1880 y erigido como principal autoridad sanitaria del gobierno nacional, y de la Administración Sanitaria y Asistencia Pública (en adelante ASyAP), dependiente del gobierno municipal de Buenos Aires, que coexistían y se repartían, no sin conflicto y superposiciones, el control sanitario del territorio que albergaba a ambos gobiernos.

La diferencia de criterios respecto del reconocimiento de los focos y de las medidas a tomar (principalmente, si establecer o no cuarentenas) generó sucesivas crisis políticas al interior de ambas instituciones, sobre todo en el DNH, que ponían de manifiesto su debilidad para posicionarse como la institución de referencia sanitaria. Sin embargo, esto no evitó que la institución, con la reestructuración interna llevada a cabo por José María Ramos Mejía durante los primeros años de la década de 1890, comenzara a ser guiada por preocupaciones más amplias, como el estudio de enfermedades rurales o las reformas en los métodos de producción de vacuna antivariólica, que estaba a su cargo (Álvarez, 2004; Di Liscia, 2011; González Leandri, 2010).

Como parte de esas iniciativas, en octubre de 1894 Ramos Mejía elevó al gobierno nacional una petición para que el director de la Sección Bacteriológica de la Oficina Sanitaria Argentina (en adelante OSA), Carlos Malbrán, viajase a Europa para realizar una estadía formativa en Berlín y París con el objetivo de adquirir el manejo de las técnicas de producción de antitoxinas y sueros terapéuticos. Esta petición fue aprobada en diciembre, al asignársele la licencia de la ayudantía de la cátedra de Anatomía Patológica de la Escuela de Medicina y una suma de $\$ 1000$ oro por un período de dos meses. ${ }^{10} \mathrm{Al}$ igual que Malbrán, también fue comisionado el vocal del DNH Francisco Silveyra, un joven médico que había sido interno del Hospital de Clínicas y realizado un trabajo experimental sobre eosinófilos de la médula ósea, en el cual retomaba algunas de las investigaciones de Ehrlich sobre leucocitos. ${ }^{11}$

En el caso de los integrantes de la ASyAP, la reacción inicial fue contraria a asumir la producción de sueros. Julio Méndez, el director del laboratorio bacteriológico de la ASyAP, afirmaba que el proceso de producción de la toxina a gran escala no era un trabajo indicado para los laboratorios de análisis, como los existentes en Buenos Aires, sino que éste debía ser llevado a cabo en institutos especializados. Méndez ampliaba sus apreciaciones afirmando que la producción de sueros debía ser llevada a cabo por una

empresa industrial como lo es ya en Alemania, habiendo pasado los límites del descubrimiento perfectamente estudiado para entrar á formar parte de los medios terapéuticos usuales, cuya preparación se conoce..$^{12}$

Si bien ambas visiones sobre la producción de sueros eran contrapuestas, la competencia por la preparación del suero estaba en marcha. El director de la OSA, Telémaco Susini, ya había iniciado, a principios de noviembre, el trabajo de producción de la toxina diftérica y la inmunización exitosa de dos caballos en el laboratorio de la Sección Bacteriológica, ayudado por Delfino y Silveyra tras su arribo. ${ }^{13}$

Es claro que el primer movimiento de Susini, al conocer los trabajos de Von Behring presentados en Budapest, consistió en negociar la conformación de una sección que requería de un establecimiento especialmente acondicionado para los caballos, la Sección Seroterápica. Esta fue creada "con urgencia" y "formalmente" en cuestión de meses, e incluida en el reglamento general de las secciones, lo que implicaba una asignación diferenciada en el presupuesto. Esta cuestión denota el poder institucional de Susini al interior del DNH, pero también el interés de la agencia en la rápida producción de sueros. ${ }^{14}$ Cuando Malbrán, director de la Sección Bacteriológica, llegó en marzo de 1895 a Buenos Aires, Susini, Delfino y Silveyra -fallecido en marzo de ese añoya habían comenzado con el procedimiento de testeo del poder inmunizante del suero, además de envasar y distribuir las primeras unidades. ${ }^{15}$

En el laboratorio de la ASyAP, a pesar de sus apreciaciones iniciales, Méndez también había comenzado a practicar la inmunización de caballos, para luego extraer el suero, envasarlo y distribuirlo. A diferencia de las investigaciones llevadas a cabo por el director de la OSA, cuyos resultados no fueron presentados en la prensa médica ni en los Anales del Departamento $\mathrm{Na}$ cional de Higiene, Méndez fue autorizado a publicar en La Semana Médica las conclusiones de su trabajo de testeo del poder inmunizante del suero, producido siguiendo la técnica de Ehrlich. ${ }^{16}$ La concreción de esos trabajos fue celebrada con una fiesta y elogiada por los principales periódicos "partidarios" cercanos al campo del poder político. ${ }^{17}$ 


\section{LAS EXPERIENCIAS CLÍNICAS Y LA RECONFIGU- RACIÓN DE LAS PRÁCTICAS PROFESIONALES}

Las estrechas relaciones que la élite médica local mantenía con la escena europea permitieron que en Buenos Aires los conocimientos prácticos asociados a los tratamientos seroterápicos comenzaran a circular casi en simultáneo a la presentación y producción masiva de los sueros en Europa, principalmente del suero antidiftérico. Los trabajos sobre la identificación de la bacteria productora de la difteria, el aprendizaje de los síntomas asociados a su etiología, los mecanismos de la inmunidad y las técnicas de producción de sueros terapéuticos, que venían a "reemplazar" a los antiguos tratamientos, fueron rápidamente discutidos en el principal círculo de agremiación médica, el Círculo Médico Argentino. Roux y Behring fueron colocados, junto a un grabado de sus rostros en La Semana Médica, en la pléyade de los grandes descubridores científicos de la civilización occidental (Souza, 2013, 127). ${ }^{18}$

Esto produjo una serie de reconfiguraciones en el plano profesional local, en al menos dos aspectos: a) una modificación de la práctica de atención de los pacientes; b) cambios en la formación médica, marcados por la divulgación del paradigma bacteriológico en nuevos espacios de enseñanza, así como la consolidación de una grupo de médicos de la nueva generación que presentaban un novedoso perfil profesional, más ligado al trabajo de laboratorio que al de la atención médica.

En el primero de estos niveles, la recepción de la seroterapia implicó la reconfiguración del tipo de atención médica practicada a nivel general, una cuestión que también fue señalada para los países en los cuales se la adoptaba como tratamiento terapéutico en el ámbito clínico (Hüntelmann, 2007; Rodríguez Ocaña, 1994; Rosenberg, 1977). Afectados por enfermedades infecciosas, los pacientes tratados con sueros eran confinados en hospitales y su evolución exhaustivamente seguida mediante la confección de un historial clínico particular. En este sentido, hasta ese momento, los hospitales de la AP se caracterizaban por ser espacios de internamiento de los enfermos crónicos, en general personas de avanzada edad, a los que se confinaba indeterminadamente. Los casos contagiosos, en cambio, requerían un tratamiento y una cura veloz para que los pacientes no se convirtieran en focos de infección en el caso de sobrevivir a la enfermedad. De acuerdo con los médicos porteños, los tratamientos químicos utilizados a hasta ese momento para tratar las enfermedades infecciosas, que incluso podían ser administrados en los domicilios de los enfermos (como en el caso de los coléricos), no aseguraban la neutralización de las bacterias presentes en sus organismos.

Es allí donde la seroterapia, que combinaba el aislamiento preventivo junto al tratamiento antitóxico en el ámbito hospitalario y el seguimiento sistemático de ciertos parámetros biológicos luego de su administración, modifica la práctica de atención, favoreciendo un nuevo tipo de intervención a nivel individual y, en consecuencia, un cambio en el nivel de la relación de los médicos y sus pacientes. ${ }^{19}$

Los médicos, por su lado, encontraron en la atención hospitalaria un espacio privilegiado para experimentar con la innovación terapéutica: los hospitales fueron el escenario en el cual los médicos de Buenos Aires experimentaron la potencia antitóxica de diversos tipos de sueros específicos (además de la difteria, el tétanos, el carbunclo, la peste bubónica y hasta cáncer, entre otros), a través de la aplicación a los pacientes, sin restricciones; y significaron de este modo un apéndice natural de los trabajos realizados en los laboratorios.

Esta dinámica fue condicionada por un proceso previo de reforma en los hospitales de la ciudad que tuvo lugar a fines de la década de 1880 . Esto implicó que en los hospitales San Roque, y sobre todo la Casa de Aislamiento, antiguos lazaretos reformados en los cuales se atendía y confinaba a los que padecían de algunas enfermedades infecciosas, principalmente la sífilis, la escarlatina y el carbunclo, comenzaran a desarrollarse ciertas capacidades de investigación. De hecho, durante estos años, pero principalmente después de 1886 -con la creación del laboratorio bacteriológico de la ASyAP- estos espacios también comenzaron a ser el escenario de prácticas científicas que se encontraban en auge en Europa. La bacteriología, que reconfiguraba completamente el modo de diagnosticar las enfermedades infecciosas, se insertó en la práctica clínica de los hospitales de la ciudad, fuertemente vinculados al laboratorio de la Asistencia Pública.

En este contexto, las primeras experiencias con la seroterapia a nivel local correspondieron al tratamiento con suero antidiftérico fabricado por Behring y Aronson, llevado a cabo por el director y el personal de la Casa de Aislamiento durante la segunda mitad de 1894 para tratar a un par de niños de la Casa de Expósitos y a una niña de Adrogué afectados por la difteria. A ellos se sumó el tratamiento de una niña, también por difteria, por el médico Luis Agote a fines de 1894. En el año siguiente, de acuerdo con Penna, el tratamiento con suero antidiftérico fue utilizado por distintos médicos en al menos otros 60 casos, tanto 
en hospitales municipales como en consultorios particulares. ${ }^{20}$ Estas experiencias luego fueron publicadas en La Semana Médica y los Anales del Circulo Médico Argentino junto a la descripción clínica de los cuadros patológicos, sentando un precedente para el resto de la escuela médica. ${ }^{21}$

En el segundo de los puntos mencionados, la formación médica, es posible ver cómo las modificaciones en el perfil de los hospitales condicionadas por esta nueva terapéutica también los posicionaron como espacios de formación. En este caso, Penna comenzó a dictar en la Casa de Aislamiento, desde el año 1894, una serie de cursos dirigidos a los practicantes de quinto año de la Escuela de Medicina. Estas "Lecciones clínicas sobre enfermedades infecciosas", reproducidas luego en las páginas de La Semana Médica, se centraban en los distintos métodos de tratamiento de las enfermedades infecciosas con orientación a la clínica, desde una perspectiva histórica que diferenciaba entre los "antiguos" y los "novedosos" tratamientos con antitoxinas y sueros. Si bien las primeras lecciones trataron sobre el sarampión y la disentería, la lección sobre la difteria fue la de mayor extensión. En esta Penna argumentaba, en defensa de la clínica, que los exámenes bacteriológicos eran complementarios al estudio de la sintomatología en la definición de un proceso mórbido, aunque celebraba el uso del suero antidiftérico como uno de los tratamientos definitivos. Esto colocaba su opinión, a la escuela médica de Buenos Aires, y a sus instituciones de higiene, en la línea de las escuelas europeas y americanas que habían adoptado el tratamiento con antitoxinas, en el eje Nueva York-Buenos Aires. ${ }^{22}$

Además de la importancia que estas lecciones tuvieron para la difusión de la seroterapia en el medio local, creemos que cumplieron una función central en la conformación de un nuevo espíritu de época, ligado a la incorporación de la medicina experimental, y en la emergencia de un nuevo rol profesional que cristalizaría en las décadas siguientes (Buschini y Zabala, 2015).

\section{CONFORMACIÓN DE ARTICULACIONES LOCALES: CONTROVERSIA DEL SUERO ANTIDIFTÉRICO Y EL EJE OFICINA SANITARIA ARGENTINA/ESCUELA DE MEDICINA}

Como hemos visto hasta aquí, la seroterapia tuvo una rápida y amplia difusión en el espacio profesional sanitario de la Buenos Aires de fin del S. XIX, y se llevaron adelante diferentes iniciativas para desarrollar capacidades locales de producción del nuevo tratamiento, lo que fue alcanzado rápidamente por el DNH y por la ASyAP. El modo en que se dieron estas diferentes iniciativas, sin una coordinación ni planificación, era un reflejo de las tensiones que se expresaban en el nivel de las instituciones encargadas de las políticas sanitarias, y supuso también una competencia entre los distintos actores involucrados. Nos interesa abordar, en la última parte de este trabajo, el análisis de una controversia en torno a la efectividad de los sueros producidos en los distintos laboratorios estatales, ya que su desarrollo -y resolución- nos permite comprender cómo se articularon las relaciones en torno a la seroterapia.

La controversia tuvo su origen a partir del tratamiento con los dos sueros antidiftéricos disponibles, el producido en la OSA y en el laboratorio bacteriológico de la ASyAP. En el caso de los primeros, este era distribuido en los hospitales y enviado a los Consejos de Higiene provinciales. El suero producido por la ASyAP, además de ser enviado a la Casa de Aislamiento, comenzó a ser comercializado a precios diferenciales. El suero era entregado gratuitamente a los "pobres de solemnidad" y vendido entre $\$ 5$ y $\$ 10$ a los que no pudieran probar esa condición. La institución requería de un permiso expedido por el DNH para distribuirlo. ${ }^{23}$

En 1895, las primeras unidades de suero de la OSA llegaron a las manos del director de la Casa de Aislamiento algunas semanas antes que las primeras unidades de la ASyAP. Penna rápidamente comunicó al director del DNH que el suero de la OSA había "dado los mismos resultados benéficos que los observados en la antitoxina de Behring y de Roux" ${ }^{24}$. Sin embargo, algunos meses después de que los sueros de ambas instituciones se distribuyeran en simultaneo, Penna denunció la ineficacia del poder inmunizante del suero de la ASyAP al director de la institución, Juan Bautista Señorans, afirmando además que los frascos remitidos "contuvieran cuerpos extraños; en uno de ellos había una hormiga". ${ }^{25}$ Penna señaló, algunos meses después, que los tratamientos con estos sueros no sólo resultaron ineficaces, sino que el cuadro en los niños tratados empeoró, llevándolos a la muerte. ${ }^{26}$ Señorans delegó inmediatamente una comisión especial y su director, Silvio Tatti, se dirigió a la Casa de Aislamiento para inspeccionar a los pacientes del establecimiento. De acuerdo con Tatti, la ineficacia del tratamiento con los sueros se debía a un diagnostico incorrecto, por parte de Penna, de los pacientes tratados. Según Tatti, Penna se había fiado del diagnóstico clínico, obviando los necesarios exámenes bacteriológicos, en particular, de las pseudo membranas diftéricas. ${ }^{27}$

Ante esta respuesta, Penna comunicó el hecho al director de la OSA. Susini no sólo se hizo eco de la denuncia, sino que también llevó a cabo un examen quí- 
mico y bacteriológico, en colaboración con Malbrán, sobre una serie de frascos remitidos por Señorans. De acuerdo con ese examen, el suero, tras comparárselo con el producido en la OSA y con suero común, revelaba contener sedimentos, un color rojizo amarillento, estar fuertemente alcalinizado y "oler a huevos podridos". El examen químico revelaba, según Susini, que el poder antitóxico y terapéutico, ensayado en chanchitos de la India, era nulo. Al considerar que los frascos remitidos habían sido recientemente envasados, Susini atribuyó la peligrosa infección de su contenido y la falta de valor terapéutico a un error en todo el proceso de elaboración, comenzando por una incorrecta producción de los medios de cultivo y aislamiento de la toxina, llevado a cabo en el laboratorio de la ASyAP. ${ }^{28}$ De acuerdo con Susini, la substancia que contenía el frasco era un medio de cultivo de bacterias proteus, saprógenas e, incluso, de las bacterias coli communis. El caso requirió de la reunión del Consejo de Higiene, en el que Susini finalmente, concluyó afirmando que el suero era "impuro", y que este hecho resultaba

grave porque la Asistencia Pública no sólo lo distribuye a los hospitales, sino que lo vende al público. Esta antitoxina que está en el comercio, ofrece, pues, un verdadero y real peligro. Un líquido no estéril es siempre peligroso usarlo en inyecciones hipodérmicas. Debe, en consecuencia adoptarse alguna medida al respecto. ${ }^{29}$

El poder institucional de Susini le permitía, apelando a las leyes de medicina y farmacia recientemente sancionadas, prohibir la distribución de las partidas de suero antidiftérico producidos en el laboratorio de la ASyAP, en un movimiento que, efectivamente, tenía el apoyo inicial del Consejo de Higiene, con Penna a la cabeza. Esta decisión podría ser reforzada por el hecho de que, a pesar de que se había aprobado en el año 1893 un Codex Medicamentarius Nacional que regulaba las técnicas de producción de los agentes medicamentosos, la rápida recepción de los procedimientos de elaboración del suero y su carácter controversial requerían de un estudio previo -llevado a cabo por una comisión especializada- para incluirlo en éste. ${ }^{30}$ Además, sólo algunos meses antes, Susini había declarado como innecesario un proyecto presentado por la ASyAP que planteaba sancionar la vacunación obligatoria de la difteria, alegando motivos tanto de seguridad, dado que ésta podía motivar el ocultamiento de casos sospechosos -especialmente en conventillos-, como la falta de certeza acerca de la eficacia del suero como medida profiláctica. ${ }^{31}$ De esta manera, el director de la OSA comenzó a perfilarse como un obstáculo para la ASyAP durante un momento de consolidación de la institución, en consonancia con la designación de un nuevo Intendente Municipal.

El director saliente del laboratorio de la ASyAP, Méndez, respondió al informe de Susini y Malbrán publicado en el diario La Nación, enviando una carta a los editores del diario. En esta carta, Méndez cuestionó el procedimiento de testeo de ambos, y, además, en conjunción con Señorans, intentó buscar el apoyo de otros médicos y bacteriólogos, incluso del italiano Giuseppe Sanarelli, el reputado director del recientemente creado Instituto de Higiene Experimental de la Universidad de Montevideo. De acuerdo con Méndez, el suero antidiftérico elaborado bajo su dirección, al igual que los sueros de Behring y Roux, podía presentar impurezas producidas eventualmente por las bacterias que, en algunos casos, pervivían en el aire embotellado durante el envasado. Éste no contenía substancias desinfectantes, dado que las mismas podían alterar la potencia antitóxica, pero la etiqueta del envase señalaba que no debía ser utilizado cuando presentara impurezas. El informe y la sanción de la OSA resultaban desproporcionados, dado que el suero había sido aplicado en numerosas ocasiones y a este no sólo le debían la vida "algunas pobres criaturas", sino que su producción no llegaba a satisfacer "los pedidos de la capital y de las provincias". ${ }^{32}$

Susini respondió señalando que, en primer lugar, las unidades remitidas por el director de la ASyAP, y posteriormente examinadas, no eran sólo una muestra seleccionada arbitrariamente, sino una serie estándar de producto elaborado por el laboratorio. Por otro lado, los exámenes fueron llevados a cabo con la presencia "confidencial" de Señorans -cuestión que, aparentemente, Tatti y Méndez desconocían-, y, por lo tanto, su legitimidad podía ser probada. La respuesta de Sanarelli, dado que no explicitaba la técnica de examen, carecía de validez. Finalmente, el rol del director de la OSA, según Susini, no consistía en polemizar sobre la "paternidad" del suero producido por Méndez, ni en minar la reputación de la Asistencia Pública:

Por lo que se refiere a la preparación del suero antidiftérico y a su prioridad, debo manifestar que desde que regresó de Europa el Dr. Malbrán, es él quien prepara la antitoxina en el Departamento Nacional de Higiene, y á la cual usada en la Casa de Aislamiento, y por muchos médicos en el público, «deben la vida algunas pobres criaturas». Mucho antes que se sangraran caballos en la Asistencia Pública. [...] como todo el mundo lo sabe, [...] se había extraído suero en la oficina sanitaria [...] cuando el Dr. Méndez, sostenía contra los directores Padilla y Araoz Alfaro, que no debía prepararse antitoxina en los laboratorios de Buenos Aires. ${ }^{33}$ 
Tan sólo algunas semanas después del cruce de cartas, Méndez afirmaba que, con la presentación de los últimos informes de la comisión nombrada por el Consejo Deliberante de la ciudad para dirimir el problema, la disputa por la sanción del suero antidiftérico impuro "se había calmado". ${ }^{34}$ En ésta última comunicación, Méndez apelaba a responder punto por punto el examen inicial practicado en la Sección Bacteriológica. Señalaba, entre otras cuestiones, que los análisis bacteriológicos practicados por Susini y Malbrán eran incompletos -dado que no se habían definido con exactitud los caracteres morfológicos y biológicos de las bacterias encontradas-, al igual que los exámenes químicos sobre la toxicidad del suero $y$, finalmente, que las experiencias con animales habían carecido del procedimiento de autopsiado. ${ }^{35}$

\section{CONSOLIDACIÓN DE LA SECCIÓN SEROTERÁPICA DE LA OFICINA SANITARIA ARGENTINA}

La "calma" a la que hacía referencia Méndez estaba acompañada del interés, por parte de las autoridades de la OSA y del DNH, en implementar procesos de estandarización de mayor rigor, y consolidar establecimientos encargados de la producción de agentes terapéuticos a gran escala. La disputa entre las autoridades de la ASyAP y la OSA por el suero antidiftérico puso de relieve que la eventual proliferación de establecimientos productores de sueros resultaba problemática para los funcionarios del DNH, y en particular de su dispositivo de control de la actividad farmacéutica, en un momento de consolidación global, y también nacional, de la industria de productos químicos y medicamentosos (Campins y Pfeiffer, 2011).

La opción por la iniciativa privada fue, de hecho, la opción del propio Méndez. Junto a Julio Lemos, uno de sus últimos aprendices en el laboratorio de la ASyAP, desarrollaron un establecimiento con el objetivo de producir antitoxinas y sueros para su comercialización, bajo el nombre de "Laboratorio de Antitoxinas", que fue inaugurado a fines de $1896 .{ }^{36}$ En ese laboratorio, Lemos y Méndez produjeron cultivos de los bacilos del ántrax, la difteria y el gonococo de Neisser, y elaboraron sueros antidiftéricos, anticarbunclosos y antisifilíticos, así como también vacunas anticarbunclosas a partir del método Pasteur. ${ }^{37}$ Aunque no fue posible analizar la trayectoria de éste establecimiento luego del cambio de siglo, su traslado durante los primeros años del 1900 desde su dirección inicial parece indicar que fue sucesivamente ampliado. ${ }^{38}$

Las motivaciones de Méndez para consolidar otro espacio de investigaciones y centrarse en la forma- ción de nuevos bacteriólogos, más allá del éxito inicial de la iniciativa, debían buscarse en el fracaso de su proyecto en el laboratorio municipal. Los intentos por posicionar a los bacteriólogos que había formado bajo su tutela no habían prosperado. Tatti, que había practicado la defensa ante los funcionarios de la OSA, no fue efectivizado en el puesto de director del laboratorio; en su lugar fue nombrado José Badía en junio de 1896, algunos meses antes de que Telémaco Susini también fuera designado director de la ASyAP por el Intendente entrante, Francisco Alcobendas. ${ }^{39}$ En simultáneo, Badía también fue nombrado Jefe de la Sección Seroterápica, junto al "ayudante preparador" Delfino y un joven veterinario, José Bidali. ${ }^{40}$

Luego de la disputa por la producción de suero antidiftérico, los agentes nucleados en torno de la OSA, liderados por Malbrán, alentaron la complejización de funciones de la Sección de Bacteriología y la Sección Seroterápica, proyectando la creación de un instituto destinado exclusivamente a la producción de antitoxinas y sueros. Esta nueva institución, por un lado, se puso en marcha con parte del "personal técnico" formado con Susini y Malbrán. Por otro, se articuló y tomó como espacio de reclutamiento social una cátedra que comenzó a dictarse en la Escuela de Medicina dedicada exclusivamente a la enseñanza de la bacteriología, autonomizándose de la enseñanza de la anatomía patológica, un antiguo anhelo de Susini. En este proceso también tuvieron el apoyo de Penna, quien había comenzado a liderar un proceso de reforma en la Casa de Aislamiento: el Consejo de la ciudad aprobó, a principios de 1894 , los planos y el presupuesto de un enorme hospital especializado en el tratamiento de las enfermedades infecciosas, cuya piedra fundacional fue colocada en agosto. ${ }^{41}$

Tras la implementación de esta serie de reformas, la Sección Seroterápica se puso bajo la dirección de Delfino en 1897. En simultáneo, la cátedra de Bacteriología fue creada en la Facultad y Malbrán fue designado catedrático titular por el Ministerio de Instrucción Pública. ${ }^{42}$ Bajo la dirección de Delfino, el principal objetivo del "personal técnico" de la Sección Seroterápica fue elaborar un suero antidiftérico que, bajo procedimientos rigurosos y estandarizados, pudiera ser producido a gran escala y distribuido bajo el control del DNH. Para ello, Delfino estableció una rígida división del trabajo entre el "personal técnico" encargado de la producción de medios de cultivos, colonias bacterianas y el aislamiento de la toxina, y el designado para las tareas de inmunización de los caballos y la extracción del suero sanguíneo. ${ }^{43}$ 
En este marco, la Sección se posicionó como la única productora de un suero específico para tratar la difteria: la ASyAP abandonó por completo el objetivo de producir sueros, y su laboratorio bacteriológico se centró solo en realizar los exámenes de los hospitales y el trabajo de prosectoría. ${ }^{44}$ Además, la Sección Seroterápica (luego llamada, junto a la Sección Bacteriológica, Instituto Bacteriológico) participó de las medidas de emergencia tomadas por las autoridades sanitarias en 1901 ante el arribo a la Argentina de la pandemia de peste bubónica, en este caso elaborando suero antipestoso y vacunas Haffkine. ${ }^{45}$

\section{EPÍLOGO}

A lo largo de este trabajo analizamos el modo en que una nueva terapéutica de las enfermedades infecciosas, la seroterapia, fue recepcionada entre los médicos de Buenos Aires durante la primera mitad de la década de 1890, y cómo ello dinamizó y reconfiguró al menos dos procesos que se encontraban en marcha.

Por un lado, el de renovación del DNH, una institución que desde principios de la década de 1880 pujaba por posicionarse como referencia en el campo sanitario. En este plano, proponemos que la seroterapia generó una nueva alianza entre el poder político, la medicina experimental y la elite médica. Esta se expresó en la integración al personal técnico del DNH de un grupo de médicos estrechamente vinculados a la recepción del paradigma bacteriológico, que tan solo

\section{NOTAS AL FINAL}

1 Anaya, Fernando (1902), Consideraciones sobre seroterapia de la peste y profilaxia de algunas enfermedades infecciosas, Buenos Aires, Casa Editora de Agustín Etchepareborda, p. 53.

2 Delfino, Juan Carlos (1903), "Trabajos del laboratorio bacteriológico del DNH", Anales del DNH, 19 (9), p. 396.

3 Esta reconstrucción narrativa se llevó a cabo a partir de Delfino, Juan Carlos (1898), La difteria y la preparación de su suero curativo, Buenos Aires, Imprenta y encuadernación de Guillermo Kraft.

4 Penna, José (1895), "Lecciones clínicas sobre enfermedades infecciosas a los alumnos del $5^{\circ}$ año por el Dr. José Penna", LSM, 2 (36), p. 349-350.

5 La Semana Médica (LSM) (1894), “Variedades”, 2 (4), p. 337.

6 Amuchástegui, Tomás (1905), Tétano y sueroterapia endovenosa intensiva, Buenos Aires, Imprenta de Emilio Spinelli.

7 Dasso, Fernando (1900), Seroterapia en el carbunclo externo del hombre, Buenos Aires, Compañía Sud-Americana de Billetes de Banco. algunos años antes se habían formado en el laboratorio bacteriológico de la Asistencia Pública, un puntal del dispositivo sanitario y de atención hospitalaria de la ciudad. Y al mismo tiempo, se hizo visible en el apoyo que las autoridades, tanto del gobierno municipal como nacional, dieron a la investigación empírica sobre distintos sueros en ocasión del conflicto por la producción del suero antidiftérico.

Por otro lado, en el plano de la práctica médica, la seroterapia se incorporó como una estrategia de atención de la población de las dos principales instituciones sanitarias, siendo rápidamente aceptada por la élite profesional en el ámbito clínico. De hecho, la producción y el uso de los sueros antipestosos fueron parte de las medidas sanitarias adoptadas cuando irrumpió la pandemia de peste bubónica en 1900 (junto con las medidas de profilaxia tradicionales como la cuarentena y la destrucción de focos epidémicos), y posteriormente reconocidas como eficaces. Los antiguos aprendices de Susini, como Malbrán, Delfino y Ramos Mejía, vinculados a la recepción del paradigma bacteriológico, así como otros médicos que se habían vinculado a estos nuevos conocimientos por distintas vías, capitalizaron este evento para consolidar su posición al interior del DNH -Malbrán, por ejemplo, fue posteriormente nombrado como presidente de la institución-. Este proceso, sin embargo, tiene un final abierto. La seroterapia tendrá una historia que surcará todo el siglo XX.

8 Anaya, Fernando (1902), Consideraciones sobre seroterapia de la peste y profilaxia de algunas enfermedades infecciosas, Buenos Aires, Casa Editora Etchepareborda.

9 Kraus, Rudolf (1916), Memoria del Instituto Bacteriológico del DNH, Buenos Aires, Talleres gráficos de J. Weiss y Preusche.

10 Registro Nacional de la República Argentina (1894), Segundo Semestre, Buenos Aires, Taller Tipográfico de la Penitenciaria, p. 658.

11 Silveyra, Francisco (1891), Breves apuntes experimentales: los eosinófilos, Buenos Aires, Compañía de Impresores y Litógrafos Kidd.

12 Méndez, Julio (1894), "Fábrica Nacional de Antitoxinas", LSM, 2 (1), pp. 15.

13 LSM (1894f), “Preparación del suero anti diftérico”, 1 (50), p. 328.

14 Ramos Mejía, José María (1898), Memoria correspondiente a los años 1892, 1893, 1894, 1895, 1896 y 1897. Presidencia del Dr. José M. Ramos Mejía, Buenos Aires, Imprenta "El Correo Español", p. 459.

15 LSM (1895a), "Suero antidiftérico", 2 (18), p. 135.

16 Méndez, Julio (1895b), "Seroterapia. Preparación del suero antidiftérico en el Laboratorio de la Asistencia Pública", LSM, 2 (36), pp. 280-281. 
17 Círculo Médico Argentino (CMA) (1895), “Crónica. Suero antidiftérico", 28 (28), pp. 363-364.

18 Araoz Alfaro, Gregorio (1894), "Los tratamientos modernos de la difteria", Anales del CMA, 17 (17), pp. 462-478.

19 Penna, José (1910), "Del contagio y de los medios más comunes de su tratamiento", en Penna, José y Madero, Horacio, La ASyAP de Buenos Aires, Tomo I, Buenos Aires, Imprenta Guillermo Kraft, pp. 91-110.

20 Penna, José (1895), “Lecciones clínicas sobre enfermedades infecciosas a los alumnos del $5^{\circ}$ año por el Dr. José Penna", LSM, 2 (36), p. 359.

21 Agote, Luis (1895), "Epidemiología. Tratamiento de la difteria por la antitoxina de Behring", LSM, 2 (4), pp. 35-37; Penna, José (1894a), “Epidemiología. Tratamiento de la difteria por el serum antidiftérico I", LSM, 2 (4), pp. 273-276; Semprun, José (1894), "Las primeras inyecciones de suero antidiftérico en Buenos Aires. El método de Behring en la Casa de Aislamiento", Anales del CMA, 27 (27), pp. 478-481.

22 Penna, José (1895), "Lecciones clínicas sobre enfermedades infecciosas a los alumnos del $5^{\circ}$ año por el Dr. José Penna", LSM, 2 (36), pp. 349-360.

23 LSM (1895e), "Serum antidiftérico", 2 (36), p. 511.

24 LSM (1895c), “Antitoxina”, 2 (36), p. 442.

25 LSM (1896a), “Opoterapia. El suero antidiftérico de la Asistencia Pública (I)", 3 No. 2, p. 197.

26 Penna, José (1896), “Opoterapia. El suero de la Asistencia Pública. La verdad sobre el asunto del suero", LSM, 3 (2), pp. 221-222.

27 LSM, “Opoterapia. El suero de la Asistencia Pública”, 3 (2), p. 217; Méndez, Julio (1895c), (1895c), "Diagnostico bacteriológico de la difteria", Anales del CMA, 27 (27), pp. 145-148.

28 CMA (1896), "El Suero anti-diftérico de la Asistencia Pública. Informe de la OSA", 19 (19), pp. 369; LSM (1896a), “Opoterapia. El suero antidiftérico de la Asistencia Pública (I)", 3 (2), pp. 197-199.

29 LSM (1896a), “Opoterapia. El suero antidiftérico de la Asistencia Pública (I)", 3 (2), p. 197.

30 Ramos Mejía, José María (1898), Memoria correspondiente a los años 1892, 1893, 1894, 1895, 1896 y 1897. Presidencia del Dr. José M. Ramos Mejía, Buenos Aires, Imprenta "El Correo Español", pp. 517-519.

31 CMA (1896a), "Vacunación antidiftérica. Informe del Dr. Susini", 19 (19), pp. 267-274.

\section{BIBLIOGRAFÍA}

Armus, Diego (2000), "El descubrimiento de la enfermedad como problema social". En: Lobato, M. (ed.), El Progreso, la modernidad y sus límites 1880-1916, Buenos Aires, Sudamericana.

Álvarez, Adriana (2004), "El rol de los lazaretos en el control del cólera y la fiebre amarilla. Buenos Aires 1870-1915", História Revista, 9 (2), pp. 287-317.

Buschini, José; Zabala, Juan Pablo (2015), “La medicina experimental en la Argentina durante la primera mitad del siglo
32 LSM (1896b), “Opoterapia. El suero de la Asistencia Pública”, $3(2)$, p. 217.

33 LSM (1896a), "Carta del Dr. Susini", 3 (2), p. 219.

34 Méndez, Julio (1896a), "Opoterapia. El suero de la Asistencia Pública”, LSM, 3 (2), p. 263.

35 Méndez, Julio (1895a), "Critica al informe del director de la OSA del DNH, Dr. Telémaco Susini, sobre la antitoxina de la Asistencia Pública", Anales del CMA, 19 (19), pp. 375-382.

36 LSM (1896), "Laboratorio de Antitoxinas", 3 (53), p. 452.

37 Méndez, Julio (1898), "Vacuna y vacunación carbunclosa", Revista de la Sociedad Médica Argentina, 6 (29), pp. 3-12; Méndez, Julio y Calviño, Juan Martín (1898), "El gonococo, su toxina y el suero", Revista de la Sociedad Médica Argenti$n a, 7$ (30), pp. 23-30.

38 Anales de la Dirección General de Salubridad Pública de la Provincia de Buenos Aires, (1901) 2 (10), pp. 406

39 Penna, José y Madero, Horacio (1910), La ASyAP de Buenos Aires, Tomo II, Buenos Aires, Imprenta Guillermo Kraft, p. 185.

40 Delfino, Juan Carlos (1920), Reseña de trabajos científicos, labor docente y cargos técnicos desempeñados, Buenos Aires, Casa Editoria de Guidi Buffarini, p. 7; Kraus, Rudolf (1916), Memoria del Instituto Bacteriológico del DNH, Buenos Aires, Talleres gráficos de J. Weiss y Preusche, p. 10.

41 Penna, José (1910), “Hospital Muñiz (Ex Casa de Aislamiento)", en Penna, José y Madero, Horacio, La ASyAP de Buenos Aires, Buenos Aires, Imprenta Guillermo Kraft, pp. 287-331.

42 Archivo Histórico de la Universidad de Buenos Aires, Caja 093, Oficios N¹979 y 5873.

43 Delfino, Juan Carlos (1898), La difteria y la preparación de su suero curativo, Buenos Aires, Imprenta y encuadernación de Guillermo Kraft.

44 Municipalidad de la Capital Federal (1896), "Supresión de la Sección Seroterapia", Memoria Presentada al Honorable Concejo Deliberante por el Intendente Municipal Dr. Francisco Alcobendas, Buenos Aires, Imprenta Mariano Moreno, p. 90; Intendencia Municipal de la Capital (1910), “VII. Laboratorio Central de la Asistencia Pública", Memorias de la Dirección General de la Administración Sanitaria correspondientes a los años 1906, 1907, 1908 y 1909, Buenos Aires, Imprenta LSM, pp. 17-18; Kraus, Rudolf (1916), Memoria del Instituto Bacteriológico del DNH, Buenos Aires, Talleres gráficos de J. Weiss y Preusche.

45 Delfino, Juan Carlos (1903), "Trabajos del laboratorio bacteriológico del DNH", Anales del DNH, Año X, № 9, pp. 393-397

XX: las trayectorias de Ángel Roffo, Salvador Mazza y Bernardo Houssay", Revista Brasileira de História da Ciência, 8 (1), pp. 22-38.

Bramanti, Barbara; Dean, Khatarine; Walløe, Lars; Stenseth, Nils (2019), "The Third Plague Pandemic in Europe", Proceedings of the Royal Society B, Volume 286, 1901, pp. 1-8.

Cunningham, Andrew; Williams, Perry (eds.) (1992), The laboratory revolution in medicine, Cambridge, Cambridge University Press. 
Rüdiger Prüll, Cay (2010), “Paul Ehrlich's Standardization of Serum: Wertbestimmung and Its Meaning for Twentieth-Century Biomedicine". En: Gradmann, Christopher; Simon, Jonathan (eds.), Evaluating and Standarizing Therapeutic Agents, 1890-1950, Nueva York, Palgrave-MacMillan.

Campins, Mónica y Pfeiffer, Ana (2011), "La importancia de las redes sociales en los orígenes de la industria farmacéutica argentina. El caso de los catalanes en Argentina", Revista de Historia Industrial, 47, pp. 17-50.

Crider, Ernest (1976), "Modernization and Human Welfare: The Asistencia Pública and Buenos Aires, 1883-1910", Tesis doctoral, Universidad de Ohio.

Di Liscia, María Silvia (2011), "Marcados en la piel: vacunación y viruela en Argentina (1870-1910)", Ciência \& Saúde Coletiva, 16 (2), pp. 409-422.

Gachelin, Gabriel (2007), "The designing of anti-diphtheria serotherapy at the Institut Pasteur (1888-1900): the role of a supranational network of microbiologists", Dynamis, 27, pp. 45-62.

González Leandri, Ricardo (2010), "El Consejo Nacional de Higiene y la consolidación de una elite profesional al servicio del Estado. Argentina, 1880-1900", Anuario de Estudios Americanos, 61 (2), pp. 571-593.

Gradmann, Christopher (2010), "The Construction of a Culture of Standardization at the Institute Pasteur (1885-1900)". En: Gradmann, Christopher; Simon, Jonathan (eds.), Evaluating and Standarizing Therapeutic Agents, 1890-1950, Nueva York, Palgrave-MacMillan.

Ginzburg, Carlo (1999), "Indicios. Raíces de un paradigma de inferencias indiciales". En: Mitos, emblemas e indicios. Morfología e historia, Barcelona, Gedisa.

Hüntelmann, Axel (2007), "Diphtheria serum and serotherapy. Development, Production and regulation in fin de siècle Germany", Dynamis, 27, pp. 107-131.

Moulin, Anne Marie (1992), "Patriarchal Science: The Network of the Overseas Pasteur Institutes". En: Petijean, Patrick; Jami, Catherine; Moulin, Anne Marie (eds.), Science and Em- pires: Historical Studies about Scientific Development and European Expansion, Kluwer, Springer Science-Dordrecht.

Opinel, Annick (2008), "The Emergence of French Medical Entomology: The Influence of Universities, the Institut Pasteur and Military Physicians (1890-c.1938)", Medical History, 52, pp. 387-405.

Opinel, Annick (2007), "The Pasteur hospital as an element of Emile Roux's anti-diphtheria apparatus (1890-1914)", Dynamis, 27, pp. 83-106.

Roberts, Lissa (2009), "Situating Science in Global History: Local Exchanges and Networks of Circulation", Itinerario, 33, pp. 9-30.

Rodríguez Ocaña, Esteban (1994), "El tratamiento de la difteria en la España de la segunda mitad del siglo XIX", Medicina e Historia, 54, pp. 6-28.

Rosenberg, Charles (1977), "The Therapeutic Revolution: Medicine, Meaning, and Social Change in Nineteenth-Century America". En: Rosenberg, Charles; Vogel, Morris (eds.), The Therapeutic Revolution: Essays in the Social History of American Medicine, Pennsylvania: University of Pennsylvania Press.

Rosenberg, Charles (1987), The care of strangers, Baltimore, Johns Hopkins University Press.

Simon, Jonathan (2008), "Monitoring the stable at the Pasteur Institute", Science in Context, 21 (2), pp. 181-200.

Souza, Pablo (2013), "Una "república de las Ciencias Médicas" para el desierto argentino: El círculo médico Argentino y la inscripción de un programa experimental en las ciencias médicas de Buenos Aires (1875-1914)", Tesis de Doctorado, Facultad de Filosofía y Letras, UBA.

Worboys, Michael (2000), Spreading germs: Disease theories and medical practice in Britain, 1865-1900, Cambridge, Cambridge University Press.

Worboys, Michael (2007), "Was there a Bacteriological Revolution in late nineteenth-century medicine?", Stud. Hist. Philos. Biol. Biomed. Sci., 38 (1), pp. 20-4. 